\title{
A LINGÜÍSTICA SERVE PARA ALGUMA COISA? QUESTÕES DE POLÍTICA LINGÜÍSTICA
}

Carlos Alberto Faraco*

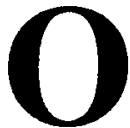

título desta conferência coloca claramente uma pergunta sobre a utilidade da linguística. Contudo, opera no terreno do equívoco ao deixar sem explicitar a continuidade da pergunta, isto é, de que utilidade estou falando; ou, ainda, para quê ou para quem a lingüística é ou não útil. Gostaria, então, de tentar resolver logo de início o equívoco posto.

Não está me interessando aqui a questão maior de se uma ciência como tal é ou não útil. Ouço muitas vezes as pessoas lançarem perguntas sobre a utilidade do estudo desta ou daquela teoria em particular; ou, ainda, perguntarem, diante de reflexões teóricas mais gerais, pela relevância prática dessa atividade, como se só fosse correto pensar cientificamente nos casos em que há um problema prático a ser resolvido.

Embora considere essas duas formas de perguntar equivocadas, não é das utilidades que elas questionam, que pretendo me ocupar aqui. Gostaria apenas de dizer que, nessa esfera, partilho da crença de que a ciência é útil mesmo quando, entregue a seus caminhos de alta idealização e abstração, parece não o ser.

Também não me interessa aqui colocar perguntas sobre a óbvia utilidade da lingüística para nós em particular que vivemos dela. Quer dizer: ela nos

* Universidade Federal do Paraná / Cefet-PR. 
garante os empregos e as bolsas e ainda nos agracia, de tempos em tempos, com momentos de agradável convívio em encontros, seminários e congressos nacionais e internacionais.

Está-me interessando aqui levantar a pergunta de se a lingüística é ou tem sido útil no espaço das nossas guerras culturais em torno da língua. Talvez seja ocioso lembrar (mas o faço, para efeitos de argumento) que a língua, como de resto qualquer outro fenômeno, é circundada e atravessada por inúmeros discursos. Até mais: a própria delimitação do que entendemos por língua, seja no interior da ciência, seja fora dela, resulta de práticas discursivas complexas e heterogêneas. E essas práticas tanto podem se complementar e se inter-iluminar, como podem se contradizer e se recusar radicalmente. É a esses encontros e confrontos que estou atribuindo a denominação de guerras culturais ou guerras discursivas em torno da língua.

Embora esses processos de intersecções e enfrentamentos ocorram tanto no interior da ciência, quanto fora dela, e haja vasos comunicantes entre aquele interior e este exterior (na medida em que não há fronteiras claras entre as diferentes práticas discursivas de uma formação social qualquer), interessa-me aqui examinar particularmente os espaços em que se contrapõem os discursos da lingüística e os discursos não propriamente científicos sobre a língua. E colocar, então, a pergunta se a linguíística tem conseguido fazer sua artilharia ressoar nessa guerra dos múltiplos discursos que dizem a língua no Brasil.

Se instado, qualquer um de nós que participa deste IV Encontro do Celsul, poderia, sem maior esforço, listar aqui, agora e rapidinho vários enunciados que remetem àquelas diferentes matrizes discursivas não científicas que dizem a língua no Brasil. Nosso colega Marcos Bagno em seus dois livros Preconceito Lingüístico e Dramática da Língua Portuguesa, deu-se ao trabalho de colecionar alguns desses enunciados, atividade que, segundo biógrafos, era um dos passatempos preferidos de Bloomfield.

Pessoalmente, não tenho ouvido, nestes últimos tempos, que a juventude não sabe mais falar e que só se comunica por meio de umas poucas expressões de gíria. Parece que essa matriz está em repouso.

Contudo, voltou a circular com muita força aquela que diz estar o português no Brasil em avançado processo de deterioração face à invasão de termos estrangeiros. Junto com essa, a de que somos um milagre lingüístico, já que, num território tão vasto, falamos uma única língua $e$, diante da invasão estrangeira, precisamos preservar essa língua em toda sua pureza.

E não podemos esquecer do renascimento bombástico, já que contando com forte apoio da mídia, do discurso que sustenta os expelidores semanais de regras, ocupados, quais zelosos pais gramaticais, em reiterar para todos nós que 
há uma só língua correta, missão que lhes é muito cara: afinal, no Brasil, ninguém (ou, para preservar esses amantíssimos pais, quase ninguém) fala certo o português...

Assim como qualquer um de nós poderia continuar arrolando outros tantos modos de dizer a língua no Brasil, também cada um de nós certamente tem seu estômago confrangido cada vez que ouve esses célebres enunciados. Afinal, tudo o que fazemos em lingüística, todas as nossas crenças, todas as nossas argumentações, todas as nossas aproximações da língua nos colocam em posição claramente antagônica a todos esses dizeres.

A questão é saber, então, se temos conseguido transformar esse antagonismo, que nos é tão claro e evidente, numa agonística. Em outros termos, a questão é saber se temos conseguido ultrapassar o ponto de apenas identificar nossos inimigos (e cavar nossas trincheiras) para atingir o ponto de transformálos em verdadeiros adversários duma luta corpo-a-corpo contínua e com efetiva repercussão social. Ou seja, interessa saber se conseguimos atingir o ponto de criar efetivas possibilidades para viabilizar uma confrontação agonística entre os discursos conflitantes.

Estou aproveitando aqui uma distinção (que me parece bastante fértil) entre antagonismo e pluralismo agonístico que a pensadora belga Chantal Mouffe utiliza em suas teorizações sobre política. Para ela e para seu parceiro intelectual, o pensador argentino Ernesto Laclau, sendo o antagonismo constitutivo de qualquer sociedade humana, é indispensável, na construção de uma desejável sociedade radicalmente pluralista e democrática, que o antagonismo seja transformado num pluralismo agonístico. Em outros termos, é indispensável que os diferentes pontos de vista, que as diferentes perspectivas sociais, que os diferentes discursos não se isolem em trincheiras, não se retirem para o espaço privado, nem exerçam o poder sem possibilidade real de contestação; mas se enfrentem franca e abertamente no espaço público.

Mouffe considera que só pela prática do pluralismo agonístico podemos ampliar, de fato, o espaço público com o objetivo não de criar consenso (daí sua polêmica com a teorização política de Habermas), mas de permitir que as diferentes posições se tornem audíveis e visíveis e que as pessoas na polis tenham a possibilidade concreta de se identificar com posições diferentes e de se colocar como contendedores das guerras políticas.

Se pensarmos que a questão da língua no Brasil não é uma questão apenas lingüística, mas, antes de tudo, uma questão política, uma questão que interessa à polis como um todo, na medida em que ela atravessa diretamente e afeta profundamente inúmeras situações sociais (bastaria lembrar aqui dos efeitos deletérios dos preconceitos lingüísticos nas nossas relaçōes sociais e, em parti- 
cular, na educação lingüística que oferecemos a nossas crianças e jovens), fica evidente que é indispensável instaurar uma prática agonística entre os múltiplos discursos que dizem a língua no Brasil; uma prática, ao mesmo tempo, receptiva à multiplicidade de vozes que circulam no espaço social e atenta à complexidade da estrutura de poder que esse sistema de diferenças implica e suas conseqüências.

Nesse sentido, volta a pergunta que estou insistindo em pôr nesta fala de encerramento do IV Encontro do Celsul: a lingüística tem servido, tem sido útil para isso? Em outras palavras: nossas práticas de ensino e pesquisa, nossas elaborações teóricas e nosso impressionante acervo de descrições do português que falamos aqui e da caracterização da complexa realidade lingüística do país têm servido para colocar nossa voz no campo das batalhas culturais como uma voz pelo menos eqüipolente com as outras vozes que dizem a língua?

Minha impressão é de que a resposta a essa pergunta é negativa. Isto é, depois de 40 anos da introdução oficial da linguiística na universidade brasileira, somos ainda invisíveis e inaudíveis para a sociedade como um todo.

Nós todos sabemos quão esquizofrênica é a sociedade brasileira em relação à questão da língua; todos sabemos como são ainda arraigados e fortes os preconceitos lingüísticos por aqui; todos conhecemos e denunciamos a miséria da educação lingüística que é oferecida na escola brasileira; todos temos inúmeros argumentos para enfrentar as matrizes discursivas não científicas que enredam a questão da língua no Brasil.

Contudo, nada do que sabemos e fazemos parece ter repercussão política para fora dos nossos arraiais. Parece que nem mesmo a maioria dos alunos que formamos em nossos cursos de graduação incorpora, até às últimas consequiências, nosso modo de dizer a língua. Boa parte deles, ao ingressar, por exemplo, no magistério, não faz mais que apenas reiterar os outros discursos.

Para dar mais chão a essas impressões algo negativas, gostaria de fazer referência a algumas situações bastante sintomáticas disso que acabo de afirmar.

Durante o período em que assinalamos, os 500 anos da chegada dos portugueses às terras que são hoje costas brasileiras, chamou-me a atenção o fato de que, dentre os vários eventos multidisciplinares com certa repercussão nacional que buscaram refletir sobre nossas muitas questões, nenhum tratou da questão lingüística. Trataram das artes, da literatura, da comida, da questão africana, da questão indígena, da construção do Estado nacional, mas nada sobre a língua. Podemos concluir que, para a sociedade brasileira, não há propriamente uma questão linguíística. Podemos concluir mais: que nosso modo de dizer a realidade linguíística nacional não conseguiu ainda se fazer ouvir a ponto 
de colocá-la como uma questão sobre a mesa, instaurando um necessário pluralismo agonístico nessa esfera. Apesar de todos os problemas lingüísticos que nos afetam, os discursos tradicionais e apenas eles têm bastado à sociedade.

É visível, por outro lado, que nossa intelectualidade em geral, pelo menos aquela que circula pela mídia, desconhece nossa voz. Sírio Possenti, em seu recente livro Mal comportadas línguas, dá alguns exemplos bem interessantes desse desconhecimento. Em geral, um intelectual da área de Ciências Humanas e Sociais no Brasil não inclui a questão da língua como uma de suas questões críticas e, quando fala da língua, apenas se faz porta-voz das matrizes discursivas tradicionais.

O mesmo se pode dizer dos jornalistas, seja das destacadas figuras da mídia impressa ou televisiva, como Jô Soares, Elio Gaspari ou Marilene Felinto, seja a grande massa de profissionais da área. Dessa grande massa (lembremos que se trata de profissionais de nível universitário), temos todos certamente bons exemplos para mostrar que nossa voz é ainda inaudivel, exemplos retirados seja de programas e reportagens, seja de entrevistas a que eles nos submetem quando algum tema de linguagem vira assunto de moda.

Do Jô Soares, o Sírio, no livro citado, colecionou uma pérola sobre as línguas africanas que, segundo ele, seriam fáceis de aprender por terem poucas palavras; e que essas poucas palavras costumam ter muitos significados. Aparentemente, uma asneira na boca de um barão douto (afinal, Jô Soares estudou na Suíça, fala fluentemente várias línguas e, portanto, não pode ser incluído entre os excluídos dos bens culturais). Contudo, como bem destaca o Sírio, antes de uma asneira, é um grosseiro preconceito lingüístico e cultural que, em outras circunstâncias, atingiria, sem maiores cerimônias, alguns modos brasileiros de falar o português.

Do Elio Gaspari, guardei sua defesa, pela voz de Madame Natasha, do projeto do deputado Aldo Rebelo (Folha de São Paulo, 17 out. 1999, p. 1-18). Nela, apenas reiteram-se os velhos argumentos que desvelam um profundo desconhecimento (novamente num profissional de não poucas qualidades) de como as línguas funcionam e de como as comunidades falantes gerem a dinâmica de suas práticas de linguagem.

Recentemente (na sua coluna de 5 de novembro último), o Elio Gaspari nos dá um exemplo bem mais complicado da inaudibilidade do discurso da linguística. Trata-se de uma entrevista com a diretora do Centro de Pesquisas da Casa de Rui Barbosa. De início, é importante destacar que o referido jornalista sustenta suas perguntas no grande presumido de que, no Brasil, falamos e escrevemos mal; de que tratamos nossa língua com descaso. 
FARACO, C. A. A lingüística serve para alguma coisa?...

O mais surpreendente desse episódio, porém, não está nas perguntas, mas nas palavras da própria entrevistada, que o jornalista apresenta como filóloga - alguém, portanto, da nossa praia.

A uma pergunta sobre as consequiências do descaso com a língua, diz ela (transcrevo, sem comentários, suas palavras, com o intuito apenas de mostrar como é complexa a questão que me ocupa aqui):

\begin{abstract}
Afora a anarquia das regências, há a transformação de verbos em substantivos (disponibilização) e de substantivos em verbos (acessar). Isso empobrece o idioma. Temos também a importação de palavras. No país do futebol, acho que não se deve engessar o idioma. Do contrário, estaríamos falando em ludopédio. Mas também não acho que devamos importar palavras latinas com sotaque inglês. É o caso da expressão mídia. Ela vem do latim medium, plural media. Em inglês, grafa-se media e pronunciase midia. Estamos escrevendo em português uma palavra latina e grafando-a com o sotaque dos outros. É curioso que esse descaso coexista com um grande interesse da população pelo uso correto do idioma. A prova disso está no sucesso que os professores Pasquale Cipro Neto e Sérgio Nogueira fazem com suas colunas na imprensa. $\mathrm{O}$ brasileiro quer escrever direito.
\end{abstract}

Ainda na área do jornalismo, mais dois a merecer referência. O primeiro é o artigo de Marilene Felinto (Folha de São Paulo, 4 jan. 2000, p. 3-2) no qual, ao constatar a qualidade ruim de alguns textos da imprensa, em especial da redação de algumas notícias, ela conclui que a razão disso está no fato de que "o português aqui [no Brasil] transformou-se num vernáculo sem lógica nem regras".

O segundo caso é o da revista Cult. Trata-se de um periódico sofisticado, voltado para um público interessado em temas de literatura (portanto, gente afinada, em princípio, com a área de letras e linguagem); periódico que tem sabido selecionar seus articulistas dentre os nomes mais respeitados na área dos estudos literários. Contudo, ao se voltar para a língua, os seus editores não conseguiram ir além do Pasquale, o que é um paradoxo, se considerarmos o projeto editorial da revista; mas sinal claro de que nós lingüistas permanecemos invisíveis e inaudíveis. 
Não quero deixar de registrar, por último, o fato de que nossa voz sequer chegou aos nossos escritores contemporâneos. Para mim, foi de todo surpreendente encontrar na boca de Luís Fernando Veríssimo a frase "Às vezes me dou conta de que não sei português", dita numa entrevista publicada no Caderno 2 de $O$ Estado de São Paulo de 30 de abril último. E ele não estava sendo irônico, na medida em que a frase aparece em meio a um conjunto de considerações sobre língua e correção gramatical.

Mas, já que falamos acima do deputado Aldo Rebelo, vamos a ele!

Todos conhecemos sua proposta de legislar sobre o uso de palavras estrangeiras. A justificativa de seu projeto de lei reúne em três páginas uma das coleções mais impressionantes de alguns dos mais arraigados preconceitos e equívocos sobre a questão da língua no Brasil.

Apesar disso, seu projeto caminha pelo Congresso Nacional sem encontrar obstáculo, o que me parece mais um sinal de que a questão lingüística não é ainda uma questão da sociedade. Se o fosse, certamente o projeto não avançaria assim sem maiores percalços, porque, de alguma forma ou de outra, o Congresso Nacional é - perdoem-me o cansado lugar-comum - uma caixa de ressonância da sociedade.

Mais curioso ainda é observar que o projeto caminha não exatamente pelas mãos de deputados conservadores, mas de deputados da assim chamada esquerda. $O$ próprio autor nela se inclui e a relatora do projeto na Comissão de Educação da Câmara foi a deputada Iara Bernardi do PT de São Paulo.

O projeto Aldo Rebelo pode ser visto apenas pelo seu lado grotesco; ou como um oportunismo, face a seus evidentes efeitos midiáticos (um deputado apenas regionalmente conhecido ganhou, graças ao projeto, imenso espaço na imprensa e consequiente notoriedade nacional). Pode parecer a muitos como algo sem importância; como uma de várias iniciativas legislativas esdrúxulas que, mesmo virando lei, terminará rapidamente esquecida pela sua óbvia inaplicabilidade.

Parece-me, porém, que a situação é bem mais complexa. É importante observar que o projeto Aldo Rebelo agrada incondicionalmente aos xenófobos, aos nacionalistas canhestros, aos autoritários em geral (vide as seções de cartas dos leitores dos principais jornais do país). E não agrada a todos esses segmentos sociais por mero acaso. $O$ projeto sustenta-se nesses discursos sociais (mesmo que o deputado negue isso); e, ao mesmo tempo, sustenta-os. Há nele um indisfarçável impulso fascista; um indisfarçável desejo de controle social, de imposição do homogêneo sobre o heterogêneo, como, aliás, em todo o gesto de legislar sobre a língua. 
FARACO, C. A. A lingüística serve para alguma coisa?...

Sobre isso, vale lembrar não só de casos históricos clássicos como a legislação lingüística de Franco e Mussolini; mas também vale incluir nessa cesta os expelidores semanais de regras que, embora sem a força daqueles ditadores, querem igualmente nos impingir um absurdo modelo único e anacrônico de língua. Comportam-se, portanto, com o mesmo impulso daquele fascismo de que nos falava Foucault, daquele fascismo que habita nossos espíritos e nossas condutas cotidianas, que nos faz amar o poder, que nos faz desejar essa coisa que nos domina e explora.

Meu objetivo, porém, não é analisar aqui esse famigerado projeto. Quero aproveitá-lo apenas como mais um argumento da asserção que fiz acima de que continuamos invisíveis e inaudíveis. O projeto Aldo Rebelo teve um mérito interessante: pôs os lingüistas brasileiros em pé de guerra, o que redundou em várias cartas enviadas ao seu gabinete, em artigos publicados em alguns jornais, em debates em nossos fóruns e na bela coletânea de textos publicada pela Associação de Lingüística Aplicada do Brasil (Alab) em seu Boletim ano 4, n. 4, de julho de 2000.

Nada disso, porém, parece ter tido qualquer ressonância. $O$ deputado continua ignorando-nos (basta ver sua entrevista publicada na revista Istó́ no fim de outubro, duas ou três semanas atrás); a imprensa definitivamente não nos enxerga entre os contendedores dessa batalha e, portanto, não busca ouvir nossa voz. Nesse sentido, é interessante analisar os editoriais da grande imprensa sobre o tal projeto: a maior parte fez crítica a ele, mas com base apenas num genérico bom senso. Em nenhum momento, nossos argumentos foram incluídos.

Não me tomem, porém, como um apocalíptico. Ao insistir em constatar que nossa voz é ainda inaudível, de que continuamos invisíveis, meu objetivo não é proclamar aqui o fim dos tempos, nem lamentar um nosso fracasso político, nem propor uma auto-flagelação coletiva dos lingüistas brasileiros. Tampouco estou querendo organizar uma cruzada para converter todos os cidadãos em lingüistas ou para silenciar as outras vozes.

Bem ao contrário. Quero apenas defender a necessidade de nos ocuparmos mais com essa questão; de trabalharmos mais essa questão como uma questão política; de buscarmos meios para projetar nossa voz e para instaurar, pelo menos, um pluralismo agonístico entre os discursos que dizem a língua no Brasil.

Me entendam bem: não estou querendo simplificar as coisas, nem passar a imagem de que unicamente nossa intervenção resolverá o assunto. Primeiro, é bom lembrar que essa situação toda não é exclusividade brasileira. Além disso, trata-se claramente de uma situação sob múltiplas determinações e, portanto, 
não há saída fácil para ela. Gostaria apenas de defender nosso empenho em tomar essa questão política mais sistematicamente.

Lembro, para encerrar, que a diretoria anterior da Associação Brasileira de Linguística, que tinha a nossa colega Leonor Scliar-Cabral, da UFSC, como presidente, deu um passo importante nesse sentido ao provocar um debate que culminou num documento que arrola considerações pertinentes com vistas à definição de uma política lingüística no Brasil.

Entendo que, embora se trate de um texto preliminar e, por isso, insuficiente, ele não pode ficar esquecido. Ele sintetiza, mesmo que ainda de forma genérica (mas com propriedade), as principais características do rosto lingüístico do país; introduz o importante conceito de direitos lingüísticos do cidadão; comenta pontos de resistência ao avanço de uma política lingüística; e, por fim, arrola algumas iniciativas para que nossa voz torne-se audível. Acredito que esse documento é um bom ponto de partida para nossas guerras culturais. Resta, ao cabo dessas considerações, convidar a todos para continuarmos a discutir aquele documento, a aprimorá-lo, a divulgá-lo e a buscar formas de implementálo.

\section{REFERÊNCIAS}

BAGNO, M. Preconceito lingüístico: o que é, como se faz. São Paulo: Loyola, 1999. . Dramática da Língua Portuguesa. São Paulo: Loyola, 2000.

POSSENTI, S. Mal comportadas linguas. Curitiba: Criar, 2000. 